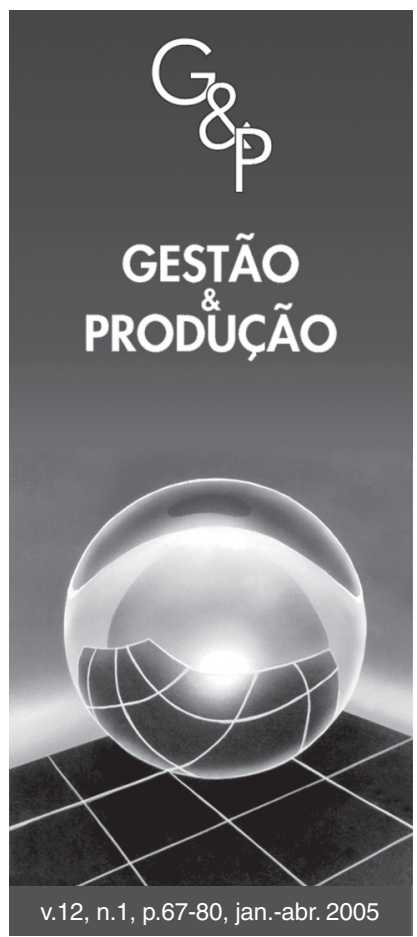

\title{
UM MODELO DE DECISÃO SOBRE A CONSIGNAÇÃO DE MATERIAL ESTRANGEIRO EM CADEIAS DE SUPRIMENTOS
}

\author{
Cristiano Morini \\ Faculdade de Gestão e Negócios, \\ Universidade Metodista de Piracicaba, \\ C.P. 68, CEP 13400-911, Piracicaba, SP, \\ e-mail: cmorini@unimep.br
}

Sílvio Roberto Ignacio Pires Programa de Pós Graduação em Engenharia de Produção, Universidade Metodista de Piracicaba, CEP 13450-000, Santa Bárbara D'Oeste, SP, e-mail: sripires@unimep.br

Recebido em 28/5/2004 Aceito em 03/3/2005

Resumo

A globalização dos negócios internacionais, o reduzido número de rotas de transporte internacional para o Brasil e a própria burocracia aduaneira pressionam as empresas industriais operando no Brasil a buscarem alternativas para reduzirem os tempos de resposta (atendimento) aos seus clientes, sem prejuízos aos custos envolvidos. Nesse sentido, este trabalho propõe um modelo de decisão voltado à gestão da consignação de materiais estrangeiros em cadeias de suprimento. Para tal, a pesquisa aplicada apresenta estudos de caso. Um elemento-chave no modelo proposto é a definição do seu conjunto de variáveis de decisão. Assim, na primeira etapa de sua construção, o conjunto de variáveis, inicialmente proposto, foi testado e ajustado com base na realidade de algumas empresas importadoras que utilizam regimes aduaneiros especiais. Posteriormente, o modelo proposto foi testado em duas empresas da região de Campinas. Os dados obtidos mostraram ser viáveis a utilização do modelo em determinadas cadeias e para determinadas características de mercadorias, aproveitando-se da legislação aduaneira nacional como oportunidade de ganho de competitividade na gestão de cadeias de suprimentos com âmbito global.

Palavras-chave: gestão da cadeia de suprimentos, consignação, material estrangeiro.

\section{Introdução}

Nos últimos anos, a gestão da cadeia de suprimentos (Supply Chain Management - SCM) tem sido considerada um novo limiar da competitividade empresarial num mundo que se globaliza em rápida velocidade. Em um país como o Brasil, o impacto da globalização também pode ser visualizado, devido ao fato de o país ser geograficamente distante dos grandes centros fornecedores de produtos de alta tecnologia e, também, dos grandes centros consumidores de produtos manufaturados, tais como os Estados Unidos da América, a Europa e o Leste Asiático.

A inserção de novos países no cenário concorrencial dos negócios internacionais, no setor industrial, foi alcançada por estratégias de redução de custos de manufatura, enquanto novas dificuldades logísticas foram agregadas ao processo, tais como problemas ligados ao desembara- ço aduaneiro de mercadorias e longos tempos de trânsito, com ciclos de fornecimento mais longos e conseqüente redução de flexibilidade (Larrañaga, 2003).

A baixa disponibilidade de rotas marítimas e aéreas para a América Latina faz com que o tempo de suprimento e distribuição de materiais torne-se maior que a média mundial. Aliada a essa característica, a tradição burocrática do Estado brasileiro, de caráter centralizador e controlador, faz com que trâmites aduaneiros se tornem barreiras na dimensão tempo, com conseqüente perda de competitividade.

Nesse contexto, este trabalho busca contribuir com a proposição de um modelo à gestão de cadeias de suprimentos, com enfoque na utilização de regime aduaneiro especial de importação, visando à diminuição do tempo de resposta ao cliente, com aumento de agilidade, 
por tornar disponível produtos para atender à demanda dos clientes. O trabalho desenvolvido considera o tempo de resposta ao cliente sinônimo do tempo de suprimento, entendido como o processo de obtenção do material, período que compreende desde a emissão do pedido de compra até o momento do efetivo recebimento.

Diante do contexto visualizado, o trabalho apresenta o objetivo de propor um modelo que contribua para a redução do tempo de resposta em cadeias de suprimentos com âmbito global, para determinadas situações, utilizando-se da legislação aduaneira nacional que possibilita a consignação de mercadoria estrangeira no país importador.

O recorte do estudo envolve temas da cadeia de suprimentos e logística focados na obtenção de materiais estrangeiros, estoque e armazenagem, bem como na legislação aduaneira aplicável a essas matérias. A associação do tema da SCM com a utilização da legislação aduaneira, na maioria das vezes, não tem sido parte do foco dos trabalhos científicos.

\section{Gestão da cadeia de suprimentos com âmbito global}

O objetivo básico na SCM é o de maximizar a integração e o de tornar realidade as potenciais sinergias entre as partes da cadeia de suprimentos, de forma a atender o consumidor final mais eficientemente, tanto por meio de redução de custos, quanto por meio da adição de valor aos produtos finais (Vollmann e Cordon, 1996).

Nesse sentido, a cadeia de suprimento deve ser visualizada como um todo, como uma entidade única, e não como algo fragmentado em grupos (Gentry, 1996). Em outras palavras, ela pode ser entendida como uma unidade de negócios formada "virtualmente" pelas empresas distintas e independentes que a compõem (Pires, 1998). Assim, cada unidade dessa virtual unidade de negócios deve se preocupar com a competitividade do produto perante o consumidor final e com o desempenho da cadeia como um todo, exigindo, portanto, a gestão integrada da cadeia (Pires, 2004).

Por sua vez, Zinn (1996) afirma que a redução de custo é, tipicamente, o melhor argumento para justificar investimentos em logística. No entanto, para Larrañaga (2003), cada vez mais as organizações estão percebendo que devem competir com base no tempo. Larrañaga (2003) afirma que a redução do tempo requerido para fornecer produtos e serviços ao cliente final é uma das maiores forças que estimulam a revisão do ciclo do pedido que, no caso de componentes importados, é bem maior que o de componentes nacionais.

A seguir, são apresentados os temas da gestão de estoque e indicadores de desempenho, como oportunidade para revisão de processos em empresas com operações globais.

\subsection{Gestão de estoque}

Pequenos níveis de estoque podem acarretar riscos por falta de itens e custos altos na obtenção de itens faltantes. Estoque grande pode implicar em investimentos adicionais por armazenagem e seu custo de manutenção, redução da disponibilidade para aplicação em outros negócios ou necessidades, e perda por obsolescência ou deterioração (Carretoni, 2000).

Na gestão de cadeias de suprimentos com âmbito global, a incerteza de demanda e os entraves dos sistemas aduaneiros, na maioria dos casos, fazem com que haja a necessidade de estoques de segurança, adicionado ao fato de que o tempo de ressuprimento depende diretamente da disponibilidade de rotas marítimas e aéreas.

Dornier et al. (2000, p. 383) afirmam que as entregas de produtos que cruzam as fronteiras nacionais estão sujeitas a complicações e atrasos imprevisíveis devido aos procedimentos aduaneiros burocráticos. Christopher e Towill (2002) afirmam que a redução do tempo de resposta significa a habilidade da cadeia de suprimentos em reagir rapidamente às variações de demanda no mercado, sejam essas em volume ou variedade.

\subsection{Medidas de desempenho}

A partir da revisão de literatura realizada quanto aos indicadores de desempenho, foram levantados os seguintes autores: Fisher (1997), Pagh e Cooper (1998), Naylor et al. (1999), Shin et al. (2000), Childerhouse et al. (2002) e Larrañaga (2003). A Tabela 1 identifica algumas contribuições da literatura, de forma resumida, para a identificação de variáveis.

Tabela 1. Indicadores de desempenho identificados na literatura de SCM.

\begin{tabular}{|c|c|}
\hline Autores & Algumas Variáveis Citadas \\
\hline Fisher (1997) & $\begin{array}{l}\text { Imprevisibilidade de demanda } \\
\text { Custos de obsolescência } \\
\text { Ciclo de vida do produto }\end{array}$ \\
\hline $\begin{array}{l}\text { Pagh e Cooper } \\
\text { (1998) }\end{array}$ & $\begin{array}{l}\text { Ciclo de vida do produto } \\
\text { Valor do produto } \\
\text { Incerteza de demanda } \\
\text { Economia de escala }\end{array}$ \\
\hline Naylor et al. (1999) & $\begin{array}{l}\text { Lead time } \\
\text { Estabilidade de demanda }\end{array}$ \\
\hline Shin et al. (2000) & $\begin{array}{l}\text { Base de fornecedores } \\
\text { Lead time de fornecimento } \\
\text { Durabilidade do produto } \\
\text { Confiabilidade de entrega }\end{array}$ \\
\hline $\begin{array}{l}\text { Childerhouse et al. } \\
(2002)\end{array}$ & $\begin{array}{l}\text { Ciclo de vida do produto } \\
\text { Variabilidade de demanda }\end{array}$ \\
\hline Larrañaga (2003) & $\begin{array}{l}\text { Velocidade para colocar produtos no } \\
\text { mercado, velocidade para atingir os volu- } \\
\text { mes de produção exigidos e rapidez das } \\
\text { organizações de gerar lucros }\end{array}$ \\
\hline
\end{tabular}




\section{Gestão de estoque e armazenagem e a legislação aduaneira nacional}

Esta seção apresenta a questão da localização do estoque e a gestão de armazenagem e seus relacionamentos com o fornecimento de itens oriundos de outros países, com ênfase na cadeia de suprimentos de indústrias de manufatura.

\subsection{O estoque e sua localização a serviço da cadeia de suprimentos}

A localização do componente estrangeiro na cadeia de suprimentos internacional, com foco no abastecimento, pode apresentar ganhos com aumento de agilidade e diminuição do tempo de resposta.

A SCM, utilizando os regimes aduaneiros especiais, pode adicionar mais valor que custo, pela localização do estoque e pela maior agilidade na resposta às variações de demanda.

Em determinados regimes aduaneiros especiais, a entrada de bens estrangeiros no país ocorre por meio de admissão, e não importação propriamente dita. Na admissão do bem, o solicitante do item no Brasil não se apresenta, ainda, no papel do comprador (importador), pois o bem é admitido sem ser feito o pagamento por ele ao seu fornecedor, ou seja, em consignação. Essa modalidade, na linguagem aduaneira, é denominada de "sem cobertura cambial". Com isto, a mercadoria admitida sem cobertura cambial é entrepostada em um armazém autorizado como permissionário de um porto seco, sob controle da Secretaria da Receita Federal, aplicando um dos regimes aduaneiros especiais, os quais são comentados adiante.

A empresa permissionária de um porto seco é um operador logístico. O material admitido no país, por intermédio de um porto seco, no regime especial de entreposto aduaneiro na importação (discutido adiante), não é propriamente da empresa que o encomenda, mas do fornecedor, que mantém o bem no país do futuro comprador, ou seja, próximo de seu mercado consumidor.

Portanto, não se pode falar em custo de estoque para a empresa que encomenda o material, mas apenas em custo de armazenagem. O estoque é do fornecedor, o custo da armazenagem é da empresa que encomenda o material, e a responsabilidade, pela guarda dos bens e confiabilidade do estoque, é do porto seco habilitado, no papel de operador logístico.

A partir do momento em que é colocada a demanda por determinado item, a empresa que encomenda o material estrangeiro torna-se compradora da mercadoria ao despachá-la para consumo, ou seja, ao propriamente promover sua importação. Nesse momento, o fornecedor recebe o pagamento pelo item que mantinha no país da empresa que encomendou o material, a qual promove o recolhimento dos impostos devidos, suspensos na admissão do item no Brasil.
O fornecedor também se beneficia com a manutenção do estoque no país do comprador, pois o ônus da armazenagem é do comprador, além de disponibilizar maior espaço em seu recinto por manter o estoque de seu produto em outra localidade.

\subsection{A legislação aduaneira brasileira e sua relaçẩo com a localidade do estoque e a gestão de armazenagem}

A existência de regimes aduaneiros especiais pressupõe a existência de regime aduaneiro comum ou normal, ou seja, o regime em que as mercadorias entram no território aduaneiro, dele saem e são transportadas por ele, cumprindo todas as exigências administrativas, fiscais e aduaneiras. Os regimes aduaneiros especiais tratam de exceções ao regime comum, principalmente por apresentarem a suspensão do pagamento dos impostos, dentre outras características.

\subsubsection{Entreposto aduaneiro}

$\mathrm{O}$ regime aduaneiro especial de entreposto aduaneiro pode ser utilizado na importação ou exportação. O regime de entreposto aduaneiro na importação é o que permite a armazenagem de mercadoria estrangeira em recinto alfandegado de uso público, com suspensão do pagamento dos impostos incidentes na importação, conforme artigo 356 do novo Regulamento Aduaneiro (Brasil, 2002b). Por ser de uso público, ele é comumente utilizado em portos secos. O tempo de permanência no regime é de um ano, prorrogável por mais um e, em situações especiais, até três anos, segundo o artigo 361 do novo Regulamento Aduaneiro (Brasil, 2002b).

\subsubsection{Os portos secos}

Em 2003, segundo dados da ABEPRA (Associação Brasileira das Empresas Operadoras de Regimes Aduaneiros), aproximadamente $20 \%$ das importações brasileiras passaram por portos secos e, das atividades desenvolvidas nos portos secos, $98 \%$ está voltada para as importações (Importados..., 2003).

Os portos secos são terminais aduaneiros de uso público, destinados à prestação dos serviços públicos de movimentação e armazenagem de mercadorias que estejam sob controle aduaneiro. Portanto, os portos secos são recintos físicos, em que podem ser operados determinados regimes aduaneiros comum e especiais, conforme habilitação do recinto.

Um porto seco tem como principal função receber mercadoria importada ou a exportar, sob controle fiscal, utilizando um dos regimes especiais em que a unidade está habilitada. O porto seco pode oferecer as seguintes vantagens (Columbia, 2002):

- proximidade do cliente, no caso de importação;

- suspensão dos impostos incidentes na importação, en- 
quanto a mercadoria se encontrar dentro do recinto em regime especial;

- maior agilidade no desembaraço aduaneiro de mercadorias, comparando-se aos portos, aos aeroportos e às fronteiras;

- custos de armazenagens mais competitivos que nas zonas primárias. Como mencionado, nos portos secos, os custos de armazenagem são de, aproximadamente, $0,10 \%$ do valor CIF, enquanto na zona primária são, aproximadamente, $1,5 \%$ do valor CIF; e

- estoque estratégico para cargas com longo lead time.

Para uma mercadoria ser entrepostada dentro de um porto seco, no regime de entreposto aduaneiro na importação, tem que se enquadrar nos seguintes requisitos (Brasil, 2002a):

a) partes, peças e outros materiais de reposição, manutenção ou reparo de aeronaves e embarcações, veículos, máquinas, equipamentos, aparelhos e instrumentos;

b) máquinas ou equipamentos mecânicos, eletromecânicos, eletrônicos ou de informática, identificáveis por número de série, importados, para serem submetidos a serviço de recondicionamento, manutenção ou reparo, no próprio recinto alfandegado, com posterior retorno ao exterior; e

c) quaisquer outros importados e consignados à pessoa física ou jurídica, domiciliada ou estabelecida no país.

\section{Metodologia de pesquisa}

Este trabalho é resultante de um projeto de pesquisa com foco na área de SCM e na área de legislação aduaneira no Brasil. A Tabela 2 apresenta uma síntese da metodologia aplicada a este trabalho.

O método utilizado é o hipotético-dedutivo de Bunge (1983 apud Lakatos e Marconi, 2001), com estudo de caso, a fim de fornecer suporte à demonstração dos argumentos apresentados na idéia do modelo proposto. O método de Bunge, o qual é aplicado neste estudo, determina as seguintes etapas a serem seguidas:

a) exposição do problema, com reconhecimento dos fatos,

Tabela 2. Resumo metodológico deste trabalho.

\begin{tabular}{ll}
\hline \multicolumn{1}{c}{ Quesito } & \multicolumn{1}{c}{ Utilizado } \\
\hline $\begin{array}{l}\text { Campos do Conheci- } \\
\text { mento Envolvidos }\end{array}$ & Interdisciplinar (Lakatos e Marconi, \\
Tipo de Pesquisa & $\begin{array}{l}\text { Exploratório, de caso (Cervo e Ber- } \\
\text { vian, 2002) e aplicada (Vergara, 2000), } \\
\text { ou seja, multimétodo }\end{array}$ \\
Método & $\begin{array}{l}\text { Hipotético-dedutivo de Bunge (Laka- } \\
\text { tos e Marconi, 2001) } \\
\text { Técnica }\end{array}$ \\
& $\begin{array}{l}\text { Documentação direta e indireta (Bian- } \\
\text { chi et al., 2003) }\end{array}$ \\
\hline
\end{tabular}

descoberta do problema, com encontro de lacunas no saber existente;

b) construção de um modelo teórico;

c) dedução de consequiências particulares, com a procura de suportes empíricos;

d) teste de hipóteses, com a determinação das observações, análise dos dados empíricos coletados e inferência da conclusão à luz do modelo; e

e) adição ou introdução das conclusões, fazendo o contraste das provas com as consequiências deduzidas do modelo teórico, reajustando o modelo, se necessário.

\subsection{Aspectos metodológicos aplicados ao modelo}

Segundo Martins (1999), modelos buscam a especificação da natureza e a importância de relações entre variáveis. O modelo é uma abstração que caracteriza idéias fundamentais com auxílio de conceitos com os quais estão familiarizados.

Segundo Zendejas (2000), existem diferentes instrumentos para a medição qualitativa: escala Likert, diferencial semântico e escala de Guttman. O instrumento de que este trabalho se vale é o da escala Likert. Segundo Pereira (2001), o sucesso da escala de Likert consiste no fato de que ela tem a sensibilidade de recuperar conceitos aristotélicos da manifestação de qualidades: reconhece a oposição entre contrários, reconhece gradiente, e reconhece situação intermediária, dentro de uma análise qualitativa. Acrescenta, ainda, que a representação aritmética de um evento qualitativo é uma estratégia para o processamento e a análise, mas a interpretação de resultados requer do pesquisador um retorno ao significado original de suas medidas.

Após a verificação das variáveis, o modelo foi revisado e apresentado a empresas de manufatura para fins de estudo de caso. Para tanto, foram realizadas entrevistas com profissionais ligados diretamente ao processo de logística de suprimentos. O instrumento básico da entrevista foi o questionário previamente utilizado, revisado com os dados coletados na pesquisa.

\section{O modelo desenvolvido}

O modelo apresenta variáveis que, uma vez aplicadas conforme determinadas condições, propõe a utilização de consignação de mercadorias estrangeiras, com o objetivo de disponibilizar mercadorias em menor tempo de ciclo.

\subsection{Apresentação das variáveis do modelo}

O modelo proposto considera as seguintes variáveis para a aplicação da lógica de consignação de material estrangeiro, utilizando-se o regime especial de entreposto aduaneiro na importação, em porto seco: 
- valor agregado;

- demanda;

- volume (em dimensões);

- ciclo de vida;

- peso;

- prazo de validade;

- "criticidade" (condição do item de ser crítico para a empresa industrial);

- necessidade de reduzir ativos fixos;

- valor do frete aéreo (em caso de falta);

- giro de estoque;

- necessidade de maior disponibilidade (ao cliente final);

- complexidade do fornecimento;

- lead time do fornecimento; e

- nível de relacionamento com o fornecedor.

A Figura 1 identifica as variáveis idealizadas para a construção do modelo. A figura está apresentada no formato de gráfico "radar". Segundo Pinto (1998), o gráfico radar pode propiciar: apresentação de várias dimensões simultaneamente; fácil visualização comparativa; e uniformização das unidades de medida dos diferentes indicadores. Essa estrutura permite colocar lado a lado diferentes tipos de indicadores. Essa uniformização das unidades de medidas pode ser considerada um dos pontos fortes do gráfico.

A área cinza simboliza os resultados a serem considerados válidos pelo modelo. $\mathrm{O}$ modelo propõe que as variáveis sejam próximas de 5 ou, minimamente, 3, para que apresentem um resultado médio de importância minimamente razoável para admissão no regime indicado em porto seco, ou seja, dentro do intervalo de 3 a 5 . A construção do modelo permite que haja pontuações situadas na área branca, desde que a média final dos resultados individuais se situe dentro do intervalo indicado, ou seja, de 3 a 5 , porque 3 representa "razoável importância", enquanto 5 representa "elevada importância", conforme discutido adiante.

Para itens e cadeias com pontuação fora da média estabelecida, não se aconselha a utilização de porto seco, seja pelo maior custo no processo, com altas despesas de armazenagem, por exemplo, seja pela dificuldade de relacionamento com o fornecedor, a ponto desse não aceitar consignar mercadorias no país comprador ou, ainda, pela escolha em utilizar o frete aéreo em situação de indisponibilidade de material, sem inviabilizar o processo pelo custo do suprimento.

Na Figura 1, para cada um dos itens a ser analisado, há uma graduação de 1 a 5, para efeitos de verificação de aplicabilidade em cada empresa industrial. O número 1 corresponde à análise do item que foi considerado muito

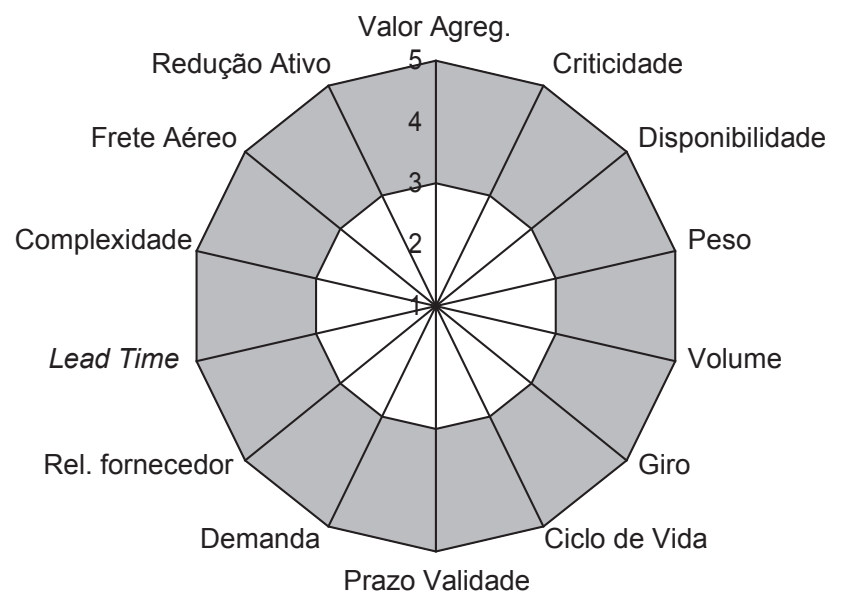

Figura 1. Variáveis do modelo (apresentação tipo radar).

baixo ou muito pequeno, sem importância. $\mathrm{O}$ número 2 corresponde ao resultado da análise do item que indicou um nível baixo ou pequeno, de pequena importância. $\mathrm{O}$ número 3 corresponde ao resultado considerado de razoável importância, bem como um ponto neutro ou indefinido da escala. O número 4 como algo importante, de nível alto ou grande. $\mathrm{E}$ o número 5 foi indicado para os resultados considerados muito importantes, de nível muito alto ou muito grande.

Há uma variedade de escalas possíveis de respostas fechadas (1 a 5, 1 a 7, 1 a 9, 0 a 4). Um critério para estabelecer o número ideal pode ser a capacidade que o respondente tem de discriminar o objeto. Como o questionário encaminhado foi endereçado às empresas, e elas definiram a pessoa competente para responder ao questionário, previu-se que este fosse respondido por profissionais de cargos diferenciados na escala hierárquica organizacional, ou seja, com capacidades diferenciadas de avaliação. Diante disso, optou-se pela escala Likert de cinco pontos ( 1 a 5), restringindo a margem de interpretação do gradiente da escala, por parte de pessoas de cargos hierarquicamente diferentes.

\subsubsection{Observações do modelo desenvolvido}

O modelo propõe que, quando as variáveis mostram indicadores associados a "grande", "alto" ou "bom", é viável a utilização de regime especial de importação mencionado em porto seco, lembrando que há uma ampla gama de relacionamentos possíveis entre as variáveis, analisadas duas a duas, três a três, quatro a quatro, e assim por diante. Nessas relações possíveis, podem existir situações em que seja viável a utilização do regime mencionado em porto seco, mesmo não sendo a variável considerada "grande". Para esses casos, as médias ponderadas dos resultados atribuídos às variáveis devem estar no gradiente de 3 a 5. 


\subsection{Redução do tempo de resposta ao cliente}

O tempo de suprimento do componente comprado do exterior pode ser entendido como a soma dos tempos indicados pelos tempos T1, T2, T3, T4, T5, T6 e T7, da seguinte maneira:

- T1 é o tempo do processamento do pedido ao fornecedor no exterior, podendo também ser entendido como lead time de compras;

- T2 refere-se ao tempo de processamento do material, faturamento e embalagem;

- T3 refere-se à coleta do item no fornecedor ou em algum ponto indicado por ele;

- T4 refere-se à estufagem do container ou caixa, despacho de exportação, espera do navio ou aeronave e embarque da carga;

- T5 refere-se ao tempo de trânsito internacional propriamente dito;

- T6 refere-se ao tempo do desembarque e desembaraço aduaneiro do item; e

- T7 refere-se ao trânsito interno da carga, do ponto alfandegado até a fábrica.
No processo de importação direta, sob o regime comum, devem ser somados os tempos (T1 a T7). Na hipótese do estoque estar disponível na fábrica, já houve o pagamento do fornecedor e o recolhimento de impostos, sendo a situação ideal em termos de disponibilidade, mas inviável economicamente na maioria das vezes. A terceira situação procura justamente evitar a desvantagem do estoque estar dentro da fábrica, o recolhimento de impostos na entrada no país, e a desvantagem do estoque estar no fornecedor no exterior. Na situação de consignação no país de destino, T2, T4 e T5 são desconsideradas para fins de nível de atendimento ao cliente industrial.

A importância de um porto seco para a cadeia de suprimentos com âmbito global relaciona-se, portanto, na prestação de serviço estratégico de estoque, mostrandose como uma ferramenta potencialmente eficaz no balanceamento das necessidades de demanda para redução de incertezas.

A Figura 2 ilustra a apresentação dos tempos conforme discutido.

\section{Verificação e análise das variáveis do modelo}

A presente seção analisa a viabilidade de utilização

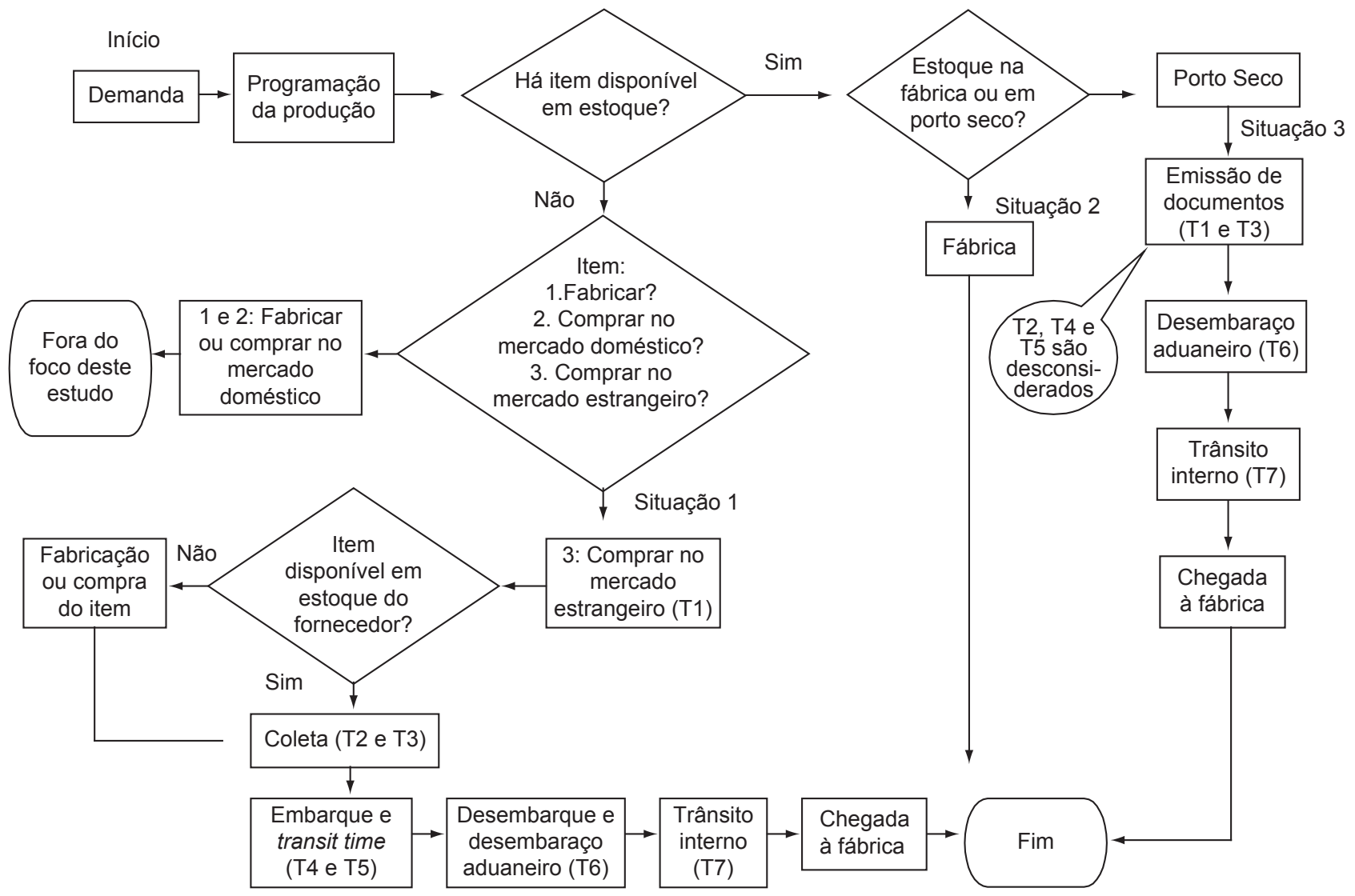

Figura 2. Fluxograma da aquisição de material pelo processo de importação comum e via porto seco. 
das variáveis inicialmente propostas e os dados coletados a partir de um questionário enviado ao universo de 142 empresas industriais importadoras e/ou exportadoras existentes no cadastro da Federação e Centro das Indústrias do Estado de São Paulo (FIESP/CIESP), Diretoria Regional de Campinas, cadastro este datado de julho de 2003. Das 142 empresas, 35 responderam ao questionário, ou seja, 24,6\% de taxa de retorno.

\subsection{Características da pesquisa de campo}

O objetivo básico do processo de seleção de empresas para a composição da amostra foi obter um conjunto de firmas representativo da região de Campinas, contido no cadastro da FIESP/CIESP, regional Campinas. O questionário foi elaborado, quanto ao tamanho ou porte da empresa industrial, segundo a Relação Anual de Informações Sociais (RAIS) do Ministério do Trabalho e Emprego. A Classificação Nacional de Atividades Econômicas (CNAE) e do Instituto Brasileiro de Geografia e Estatística (IBGE) definiram a atividade econômica da indústria.

\subsubsection{Temas do questionário}

O questionário contém um total de sete perguntas fechadas, organizadas da seguinte maneira:

a) três perguntas gerais: caracterização da empresa industrial quanto à atividade econômica, percentual de componentes importados do total de comprados e porte da empresa. Essa parte se caracteriza como a parte introdutória e geral do questionário; e

b) quatro perguntas sobre os regimes aduaneiros especiais: se a empresa utiliza os regimes aduaneiros especiais e o local de utilização desses regimes. Essa parte se caracteriza como o de perguntas específicas do questionário, ligado ao objeto de estudo da pesquisa.

\subsection{Síntese dos resultados obtidos}

Com os resultados obtidos, pôde-se perceber que, sobre a atividade econômica da indústria, 42,5\% está ligada à fabricação de veículos automotores, peças, máquinas e equipamentos.

Quanto ao tamanho ou porte da empresa, A RAIS define microempresa como aquela contendo de 1 a 19 empregados, pequena empresa, contendo de 20 a 99 empregados, média empresa, contendo de 100 a 499 empregados, e grande empresa, como aquela contendo mais de $500 \mathrm{em}$ pregados. A pesquisa revelou que $17,1 \%$ das empresas são de micro e pequeno portes, sendo $40 \%$ das empresas de porte médio e $42,8 \%$ das empresas de grande porte.

São significativas as compras efetuadas do exterior para essas empresas pesquisadas, pois $25,7 \%$ das empresas compram acima de $50 \%$ do total de itens do exterior, enquanto $48,5 \%$ compram na faixa de 10 a $50 \%$. A revisão da cadeia de abastecimento com âmbito global mostrou-se, assim, oportuna.

\subsection{Análise dos resultados obtidos}

Com relação à atividade industrial da empresa respondente, os fabricantes de veículos automotores e peças são as empresas que mais utilizaram o EAI.

O modelo proposto utiliza o entreposto aduaneiro na importação em porto seco. Os dados coletados revelam que, de fato, o local de maior utilização desse regime é o porto seco, para $42,8 \%$ das empresas que utilizam este regime, lembrando que este regime também pode ser utilizado em portos, aeroportos e fronteira, ou seja, na zona primária.

Das 35 empresas entrevistadas, 12 utilizam-se do regime de entreposto aduaneiro especial em porto seco, das quais se notou o seguinte, com relação às 14 variáveis sugeridas:

a) a análise do indicador "necessidade de redução de ativos fixos" aponta que as empresas não o consideram como importante ou de razoável importância, tendo obtido a média final de 2,5. O valor está exatamente entre 2 e 3, ou seja, entre "pouco importante" e "de razoável importância". Assim, como o valor está exatamente entre 2 e 3, ou seja, entre "pouco importante" e "de razoável importância", optou-se por retirar este indicador do modelo a ser verificado, provocando o primeiro ajuste no modelo inicial;

b) a análise de sete indicadores (giro de estoque, disponibilidade, valor agregado, volume, peso, ciclo de vida e criticidade) registrou médias entre a pontuação 2,6 e 3,5. Dentro deste intervalo, considerou-se que 2,6 está mais próximo de 3 que de 2. Portanto, foram considerados de "razoável importância" ou "importantes", considerando o centro do intervalo como sendo 3 , e receberam peso 1 para fins de aplicação do modelo, a ser verificado em estudo de caso. A determinação de diferentes pesos para as variáveis do modelo constitui-se em outro ajuste a ser efetuado no modelo; e

c) a análise de seis indicadores (complexidade, lead time, demanda, prazo de validade, frete aéreo e relacionamento com o fornecedor) registrou médias entre a pontuação 3,6 e 4,5, tendo o 4 como o centro do intervalo, ou seja, foram considerados "muito importantes" ao se trazer uma mercadoria do exterior e admiti-la no regime de entreposto aduaneiro na importação, em porto seco. Portanto, esses indicadores receberam peso 2 para fins de aplicação do modelo, a ser verificado em estudo de caso.

A Equação 1 mostra a forma de cálculo da média ponderada das treze variáveis a serem verificadas em empresas no estudo de caso.

$$
\mathrm{PMV}=\frac{\left(\mathrm{Peso}_{1} \cdot \mathrm{V} 1\right)+\left(\mathrm{Peso}_{2} \bullet \mathrm{V} 2\right)+\ldots .+\left(\mathrm{Peso}_{\mathrm{n}} \bullet \mathrm{Vn}\right)}{\left.\mathrm{Peso}_{1}+\mathrm{Peso}_{2}+\ldots .+\mathrm{Peso}_{\mathrm{n}}\right)}
$$

em que: PMV é a Pontuação Média das Variáveis e V1, V2, Vn são as pontuações obtidas nas respectivas variáveis. 
A Figura 3 mostra a média dos resultados obtidos pela pesquisa.

É importante ressaltar que o intervalo idealizado pelo modelo, inicialmente, por variável, é o situado entre 3 e 5 , e que o intervalo visualizado acima está considerando a média dos resultados obtidos pelas 12 empresas respondentes que já utilizam o EAI em porto seco, para fins de verificação de importância das variáveis.

\subsection{Avaliação final do modelo desenvolvido}

Das quatorze variáveis idealizadas inicialmente pelo modelo, para viabilizar a admissão de mercadoria estrangeira aos moldes do VMI, apenas uma delas, "redução de ativo", foi descartada pela incerteza do resultado apresentado, 2,5, exatamente o meio entre 2 e 3 , entre "pouca importância" e "razoável importância".

O modelo considera que, se as treze variáveis forem consideradas e a média ponderada das pontuações atribuídas a essas variáveis estiver dentro do intervalo de 3 a 5 , significa que a mercadoria e a cadeia de suprimentos será beneficiada com a adoção do modelo. Caso o resultado apresentado pela empresa mostre uma pontuação fora do intervalo de 3 a 5 , pelas características da cadeia de suprimentos de determinada empresa industrial, não é viável a consignação de material estrangeiro no país de destino, porque o item e a cadeia apresentam características que permitem que a mercadoria possa ser importada diretamente do exterior, quando identificada a necessidade, sem gerar impacto de custo com despesas de armazenagem no país de destino.

Assim, como contribuição, o modelo propõe treze variáveis a serem analisadas pelas empresas industriais como forma de viabilizar a agilidade do processo de suprimento internacional, sem causar perda de competitivi- dade devido ao ônus do estoque de segurança, mantido no destino pelo fornecedor.

\section{Verificação da aplicabilidade do modelo desenvolvido}

A técnica de estudo de caso é descrita por Yin (1994) como um estudo empírico que investiga um fenômeno contemporâneo em seu contexto real, e deve conter pelo menos quatro aplicações na pesquisa de avaliação: explicar os vínculos causais na intervenção na realidade, descrever o contexto real, explorar as situações nas quais a intervenção está sendo avaliada, e beneficiar a avaliação. As empresas que colaboraram com a pesquisa nessa etapa foram a Belgo e a Stork Prints.

\subsection{Belgo}

Em 1917, foi criada na cidade de Sabará, Minas Gerais, a Companhia Siderúrgica Mineira. Em 1921, em assembléia de acionistas para aumentar seu capital, a Companhia Siderúrgica Mineira teve ações adquiridas pelo grupo belgo-luxemburguês Arbed. Em 1995, adquiriu a Dedini S/A Siderúrgica, em Piracicaba, Estado de São Paulo, investindo na recuperação do setor de laminados. A fábrica da cidade de Piracicaba é do porte de uma grande empresa, com mais de 500 empregados. Em 2001, a Belgo se uniu à empresa francesa Usinor e à espanhola Aceralia, criando o grupo Arcelor.

Com o aumento da capacidade de produção da planta de Piracicaba até o final de 2005, de 400 mil toneladas de aço para 1 milhão de toneladas, devido à evolução do mercado mundial e à localização estratégica da usina, no Estado de São Paulo, está sendo redesenhado o processo de suprimentos da empresa.

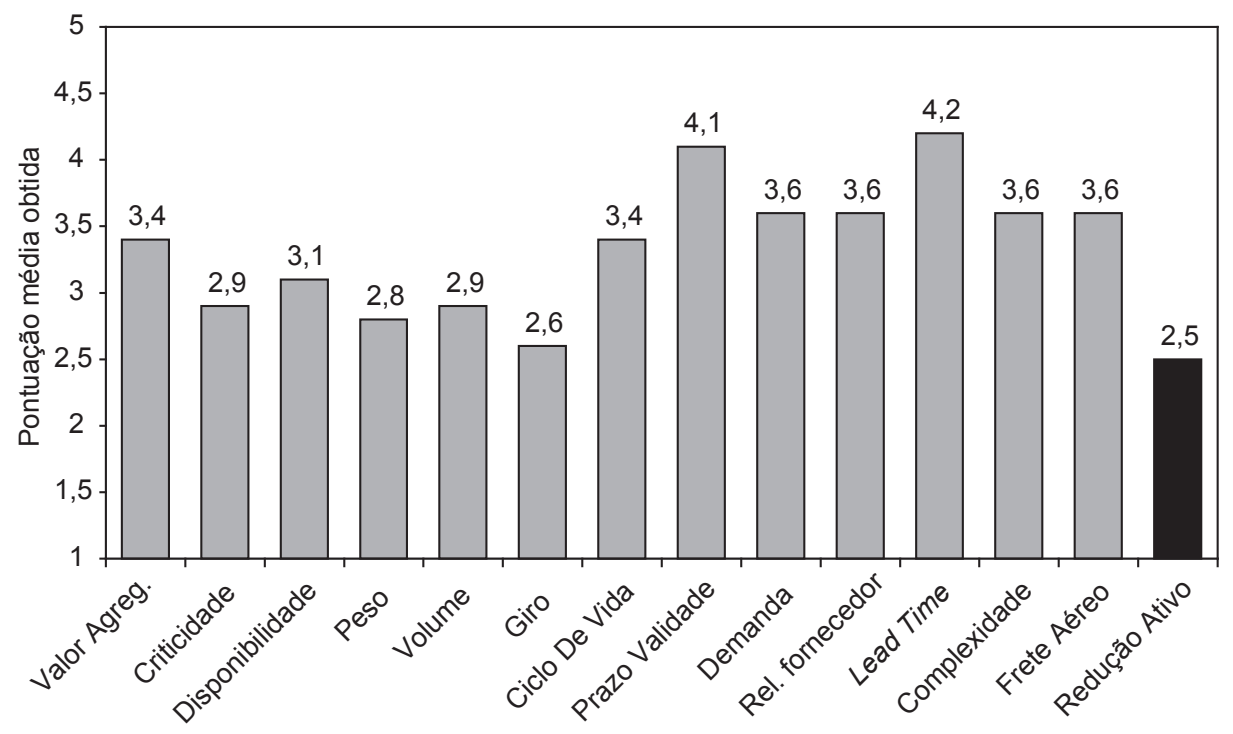

Figura 3. Média dos resultados obtidos por variável. 
O entrevistado, no cargo de gerente de suprimentos da planta de Piracicaba, afirmou utilizar este procedimento devido ao lote de aquisição ser grande e ao alto valor da compra, além da possibilidade de nacionalizar as mercadorias conforme a necessidade. O respondente afirmou que as plantas de Minas Gerais utilizam-se dos portos secos de Juiz de Fora e Jacareí.

O respondente disponibilizou informações sobre três tipos de mercadorias, consideradas de características de planejamento da produção semelhantes: lingoteiras, eletrodo de grafite e refratários, sendo itens fornecidos, principalmente, pela Alemanha. O respondente manifestou interesse em verificar a aplicação do modelo, além dessas mercadorias, também para itens de manutenção da fábrica ampliada.

\subsubsection{Verificação do modelo}

O PMV obtido foi de 4,31, mostrando ser viável à utilização do regime mencionado.

Com esse resultado, a aplicação do modelo pôde ser verificada, uma vez apontada a média aplicável sendo válida entre o intervalo de 3 a 5 na escala Likert. A Figura 4 mostra o gráfico tipo radar com a aplicação da pontuação obtida na empresa Belgo, unidade Piracicaba.

As características do processo que permitem visualizar a aplicação do modelo são as seguintes (pontuação igual ou maior que 3 ):

a) a variável denominada "valor agregado" foi considerada muito grande ou muito importante;

b) a variável "criticidade" foi indicada como muito importante, porque as matérias-primas e o produto intermediário causam impacto direto no processo produtivo, que funciona 24 horas por dia, 365 dias por ano;

c) a variável "necessidade de maior disponibilidade" foi especialmente destacada pelo entrevistado, que afirmou ser este o principal objetivo da fábrica ampliada de Piracicaba, fundamental para a própria existência do negócio, sem onerar o custo de estoque;

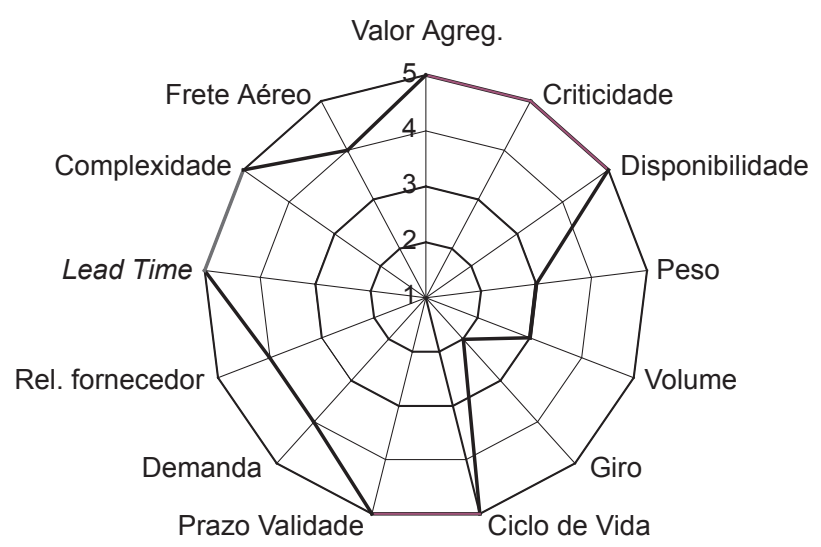

Figura 4. Gráfico radar aplicado à Belgo. d) a variável "peso" foi apontada como de razoável importância;

e) a variável "volume" também foi apontada como de razoável importância, mas, especificamente, no caso do refratário, seu volume é bastante grande, pois é uma peça única utilizada para revestir o forno da usina, para evitar que o metal do forno se funda com o aço que está sendo preparado;

f) o ciclo de vida do produto foi considerado muito grande, praticamente de prazo indeterminado;

g) o prazo de validade também foi considerado muito grande;

h) a demanda foi considerada muito grande, principalmente com a ampliação da fábrica;

i) o nível de relacionamento com o fornecedor foi considerado importante, porque o fornecedor atual atende às demandas de todas as fábricas do grupo, nos países mencionados, também sendo do tipo global sourcing. $\mathrm{O}$ respondente afirmou que o fornecedor é muito mais preocupado com o cliente que este com seu fornecedor, devido ao imenso tamanho do negócio da Belgo;

j) o lead time do fornecimento foi considerado muito grande, daí também a necessidade de maior disponibilidade do produto;

k) o fornecimento das mercadorias da origem ao Brasil foi considerado muito complexo; e

1) o valor do frete aéreo, em caso de indisponibilidade de material, foi considerado alto, para o caso da lingoteira, e proibitivo, no caso do refratário e do eletrodo. Aliás, devido ao grande volume em dimensões do refratário e do eletrodo, apenas o transporte marítimo é viável.

A Tabela 3 apresenta os números que comprovam que a redução no tempo do suprimento, com estoque mantido no país de destino, é significativamente menor que o tempo de suprimento ao ser colocado pedido para o fornecedor que mantém seu estoque na origem. Na coluna cinza, o fornecimento no processo de importação direta. $\mathrm{Na}$ coluna branca, o fornecimento com o estoque mantido no país de destino.

\subsection{Stork Prints}

A fundação da Stork é datada de 1827, na Holanda. O grupo, presente em 18 países, conta com 16.000 empregados, 12.000 na Holanda. A planta de Piracicaba conta com 110 empregados, sendo uma empresa de porte médio, com foco na tecnologia de impressão digital têxtil, com aplicações em decoração, propaganda, confecção e obras de arte. A atividade econômica da planta de Piracicaba é a de produtos de metal, exceto máquinas e equipamentos.

A empresa utiliza mais de 50\% de componentes importados do total de itens comprados. O item seleciona- 
Tabela 3. Comparativo do tempo de suprimento na Belgo.

\begin{tabular}{|c|c|c|c|c|c|c|c|}
\hline & & \multicolumn{6}{|c|}{ Belgo } \\
\hline & & \multicolumn{2}{|c|}{ Lingoteira } & \multicolumn{2}{|c|}{ Refratário } & \multicolumn{2}{|c|}{ Eletrodo } \\
\hline & & Dias & Dias & Dias & Dias & Dias & Dias \\
\hline T1 & Tempo de emissão do pedido & 15 a 20 & 1 & 15 a 20 & 1 & 15 a 20 & 1 \\
\hline $\mathbf{T 2}$ & $\begin{array}{l}\text { Tempo do fornecedor } \\
\text { Tempo de processamento do material } \\
\text { Faturamento e embalagem }\end{array}$ & 150 & 0 & 90 & 0 & 75 & 0 \\
\hline T3 & $\begin{array}{l}\text { Tempo de trânsito interno (no país de origem) } \\
\text { Embarque do fornecedor para operador logístico } \\
\text { Embarque do fornecedor para porto/aeroporto } \\
\text { Emissão de documentos }\end{array}$ & 5 a 35 & 1 & 5 a 35 & 1 & 5 a 35 & 1 \\
\hline & Emissão de documentos pelo comprador & & 1 & & 1 & & 1 \\
\hline T4 & $\begin{array}{l}\text { Tempo para operações logísticas na origem } \\
\text { Estufagem do container/caixa } \\
\text { Despacho de exportação } \\
\text { Espera do navio/avião } \\
\text { Embarque na unidade internacional de transporte }\end{array}$ & 10 & 0 & 10 & 0 & 10 & 0 \\
\hline T5 & $\begin{array}{l}\text { Tempo de trânsito internacional } \\
\text { (para o país de destino) }\end{array}$ & 20 & 0 & 20 & 0 & 20 & 0 \\
\hline T6 & $\begin{array}{l}\text { Tempo para operações logísticas no destino } \\
\text { Desembarque de carga } \\
\text { (ou separação em lotes conforme necessidade) } \\
\text { Despacho de importação } \\
\text { Conferência fiscalização SRF } \\
\text { Conferência fiscalização MA }\end{array}$ & 10 & $\begin{array}{l}0,5 \\
0,5\end{array}$ & 10 & $\begin{array}{l}0,5 \\
0,5\end{array}$ & 10 & $\begin{array}{l}0,5 \\
0,5\end{array}$ \\
\hline T7 & $\begin{array}{l}\text { Tempo de trânsito interno } \\
\text { (no país de destino, em dias) }\end{array}$ & 0,25 & 0,05 & 0,25 & 0,05 & 0,25 & 0,05 \\
\hline TT & Tempo Total (em dias corridos, aproximado) & 210 a 245 & 3 & 150 a 185 & 3 & 135 a 170 & 3 \\
\hline
\end{tabular}

do pelo respondente para fins da entrevista foi o cilindro rotamesh, utilizado para impressão têxtil para aplicações promocionais, de embalagem e outros. A Stork da Holanda é a fornecedora exclusiva desse item, e o fabrica para estoque. São importados em média 1.000 cilindros por ano, via aérea, devido ao seu baixo peso unitário.

\subsubsection{Verificação do modelo para o cilin- dro rotamesh}

O PMV obtido foi de 2,84. Com esse resultado, a aplicação do modelo não pôde ser verificada, uma vez apontada a média aplicável sendo válida entre o intervalo de 3 a 5 na escala Likert. A Figura 5 mostra o gráfico tipo radar com a aplicação da pontuação obtida.

As características do processo que permitem visualizar a não aplicação do modelo são as seguintes (pontuação inferior a 3):

a) a variável "volume" foi considerada muito pequena pelo respondente;

b) a necessidade de maior disponibilidade foi considerada muito baixa, pois o cliente aceita eventuais alterações de data de entrega;

c) o peso foi considerado também muito pequeno, pois o cilindro pesa aproximadamente 200 gramas;

d) o valor agregado do item foi considerado pelo respondente como pequeno;

e) o lead time de fornecimento também foi considerado pequeno, pois o fornecedor mantém itens em estoque para pronta-entrega;

f) a complexidade foi considerada muito pequena e é um item que tem LI automático, apesar do fornecedor estar situado no continente europeu; e

g) o valor do frete aéreo (em caso de falta do material) é considerado muito pequeno, pois não causa impacto no valor de venda da mercadoria. É importante lembrar que $100 \%$ do fornecimento do item é feito via aérea.

Com a pontuação obtida pela entrevista, não foi possível verificar a aplicabilidade do modelo, ou seja, o processo de importação deve continuar sendo feito da ma- 


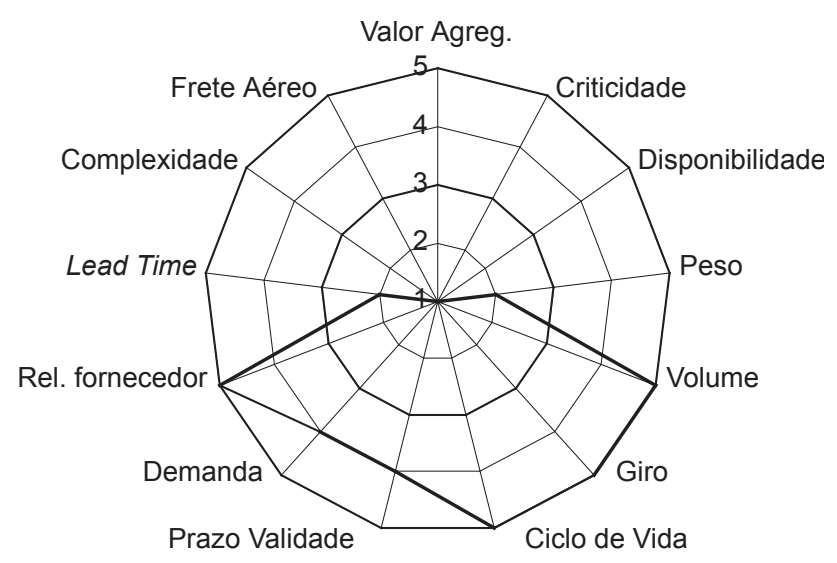

Figura 5. Gráfico radar aplicado à Stork Prints (ref. rotamesh).

neira convencional, sem a utilização de regime especial em porto seco, porque é mais viável realizar a importação por via aérea, próximo do momento da necessidade. $\mathrm{O}$ custo da armazenagem no destino onera o processo, sem beneficiá-lo. Além disso, como o valor do produto é baixo, pouco é o impacto em manter o item em estoque dentro da fábrica, já nacionalizado.

\subsubsection{Verificação do modelo para o níquel}

O níquel, o metal, é a principal matéria-prima da manufatura do cilindro utilizado para impressão digital têxtil. São dois os fornecedores de níquel: um situado nos EUA, do qual é comprado $80 \%$ da demanda, e outro situado no Brasil, do qual é comprado o restante.

O níquel do fornecedor nacional é em flocos no formato quadrado, e gera entre 5 a $7 \%$ a mais de resíduo industrial que o correspondente dos EUA. Dessa maneira, a produtividade do produto importado é maior, além dos flocos serem de formato redondo, o que permite maior aproveitamento do espaço no forno.

O entrevistado, no cargo de assistente de comércio exterior, afirmou que o fornecedor nacional é mantido como uma alternativa ao produto importado, daí a compra de $20 \%$ da demanda total, mantendo-o ativo.

O fornecedor dos EUA também é o fornecedor para todas as outras fábricas Stork do mundo, apresentando característica de global sourcing, e sistema produtivo MTS. A Stork da Holanda negocia, anualmente, um contrato de compra mundial com o fornecedor dos EUA, a fim de atender à demanda de todas as fábricas do mundo.

Obteve-se o PMV de 3,42. Com esse resultado, a aplicação do modelo pôde ser verificada, uma vez apontada a média aplicável sendo válida entre o intervalo de 3 a 5 na escala Likert. A Figura 6 mostra o gráfico tipo radar com a aplicação da pontuação obtida, e a Tabela 4, a pontuação individualizada, por variável.

As características do processo que permitem visuali-

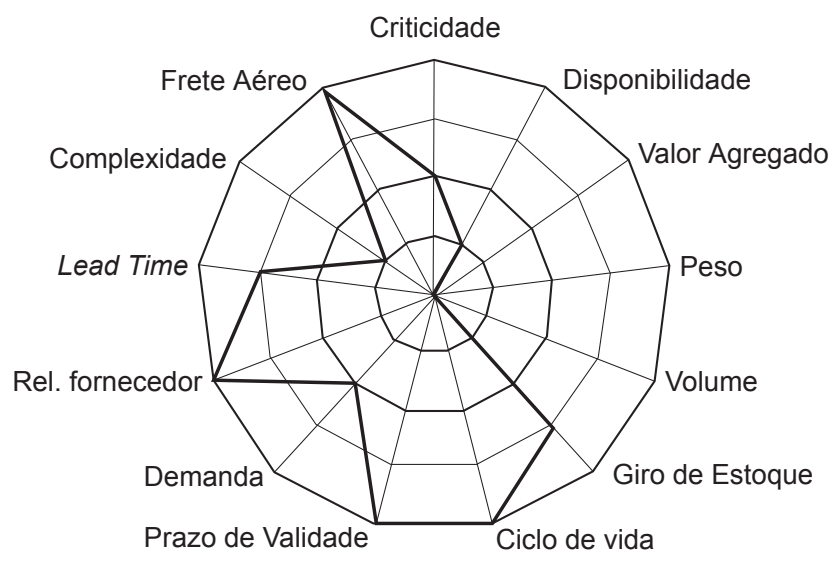

Figura 6. Gráfico radar aplicado à Stork Prints (ref. níquel).

zar a aplicação do modelo são as seguintes (pontuação igual ou maior que 3 ):

a) a variável "criticidade" é considerada de razoável importância, ou seja, é possível substituir a mercadoria importada pela do fornecedor nacional, embora ocorra perda de produtividade e aumento de resíduo do processo industrial. O cilindro de impressão têxtil é $100 \%$ níquel, ou seja, sem ele não há cilindro;

b) a variável "giro de estoque" foi considerada de nível alto, o que viabiliza a rotatividade da mercadoria admitida em porto seco, uma vez que o prazo de admissão nesse recinto, dentro do regime de entreposto aduaneiro na importação, é de um ano;

c) o ciclo de vida do produto é considerado muito grande, praticamente de tempo indeterminado, uma vez que o níquel é utilizado no processo produtivo de cilindros para impressão têxtil há mais de oitenta anos;

d) o prazo de validade também é considerado muito grande, indefinido, pois o item não se torna perecível;

e) a demanda é considerada de nível razoável no processo produtivo;

f) o relacionamento entre o fornecedor e a Stork Prints sediada na Holanda é de nível muito bom. O relacionamento do fornecedor dos EUA com a Stork Prints Brasil é bom, embora o contrato seja negociado pela corporação mundial, como informado, e o relacionamento Brasil-EUA seja apenas em nível operacional e não gerencial, como na direção Holanda-EUA;

g) o lead time de fornecimento é considerado alto, pois todos os embarques são feitos via marítima e o lead time de manufatura do níquel também é alto; e

h) o valor do frete aéreo, no caso de indisponibilidade do item, é tão alto que torna o custo do processo proibitivo.

A Tabela 4 apresenta um comparativo dos tempos de suprimento pelo processo comum de importação e pelo 
Tabela 4. Comparativo do tempo de suprimento na Stork Prints.

Stork Prints

\begin{tabular}{|c|c|c|c|c|c|}
\hline & & & Níquel & \multicolumn{2}{|c|}{ Cilindro } \\
\hline & & Dias & Dias & Dias & Dias \\
\hline T1 & Tempo de emissão do pedido & 3 & 1 & 2 & 1 \\
\hline \multirow[t]{3}{*}{$\mathbf{T} 2$} & Tempo do fornecedor & 15 & 0 & 4 & 0 \\
\hline & Tempo de processamento do material & & & & \\
\hline & Faturamento e embalagem & & & & \\
\hline \multirow[t]{5}{*}{ T3 } & Tempo de trânsito interno (no país de origem) & 1 & 0 & 1 & 1 \\
\hline & Embarque do fornecedor para operador logístico & & & & \\
\hline & Embarque do fornecedor para porto/aeroporto & & & & \\
\hline & Emissão de documentos & & & & \\
\hline & Emissão de documentos pelo comprador & & & & 1 \\
\hline \multirow[t]{5}{*}{ T4 } & Tempo para operações logísticas na origem & 7 & 0 & 3 & 0 \\
\hline & Estufagem do container/caixa & & & & \\
\hline & Despacho de exportação & & & & \\
\hline & Espera do navio/avião & & & & \\
\hline & Embarque na unidade internacional de transporte & & & & \\
\hline T5 & Tempo de trânsito internacional (para o país de orgiem) & 18 & 0 & 1 & 0 \\
\hline \multirow[t]{5}{*}{ T6 } & Tempo para operações logísticas no destino & 7 & 0,5 & 2 & 0,5 \\
\hline & Desembarque da carga (ou separação em lotes conforme necessidade) & & 0,5 & & 0,5 \\
\hline & Despacho de importação & & & & \\
\hline & Conferência e fiscalização SRF & & & & \\
\hline & Conferência e fiscalização MA & & & & \\
\hline T7 & Tempo de trânsito interno (no país de destino, em dias) & 0,25 & 0,05 & 0,05 & 0,05 \\
\hline TT & Tempo Total (em dias corridos, aproximado) & 51 & 1,5 & 13 & 3 \\
\hline
\end{tabular}

Processo de importação direta

Processo de importação via porto seco

processo de utilização de estoque no país de destino na importação, em porto seco. É visível o tempo de suprimento bastante superior na situação de importação direta do item do exterior (coluna cinza). No caso específico do cilindro rotamesh, embora haja redução significativa do tempo de suprimento, as características da mercadoria e da cadeia não demonstram viabilidade de se utilizar o estoque no destino, sendo mais viável importar o item, via aérea, no momento de sua necessidade.

\subsection{Conclusão geral da aplicação do mo- delo nas empresas}

Pôde-se perceber que uma das empresas, a Belgo, aceitou muito bem a pesquisa conduzida, pois já estava em fase de redefinição de seu processo de suprimentos. O modelo pôde ser confirmado na Belgo, fábrica de Piracicaba. Os benefícios do modelo são claramente identifi- cados no caso da Belgo: redução do imobilizado, com redução do tempo de suprimento. A redução desse tempo é inerente ao processo de utilização de estoque no destino.

No caso específico do cilindro rotamesh, da Stork Prints, a verificação do modelo mostrou que as características do item e do abastecimento inviabilizam a utilização do regime de entreposto aduaneiro na importação, conforme foi mostrado pelo modelo. $\mathrm{O}$ fato do modelo ter-se mostrado inválido para o caso do cilindro rotamesh serviu como contraprova de que o modelo tem sua aplicabilidade em situações definidas, ou seja, de acordo com certas características das variáveis apresentadas no modelo.

Ficou claro, para os entrevistados, que a aceitação do fornecedor em consignar mercadorias no Brasil é viável para a cadeia de suprimentos das empresas envolvidas, conforme a avaliação das variáveis do modelo. Pôde-se perceber que as constantes atualizações da legislação e 
os desafios burocráticos aduaneiros cotidianos fazem por dificultar a redefinição de processos e estudos de viabilidade, como o desenvolvido nesta pesquisa.

\section{Considerações finais}

O trabalho propôs um modelo teórico para guiar o processo de decisão na determinação da viabilidade de consignação de mercadoria estrangeira, com o fim de reduzir o tempo de suprimento, sem perda de competitividade provocada pela despesa de armazenagem.

O modelo teórico tem como característica intrínseca a redução do tempo de resposta na SCM com âmbito global, fundamentando-se no aproveitamento da legislação aduaneira brasileira que, embora datada dos anos 1960, vem se aperfeiçoando e se modernizando com o tempo, devido às novas exigências nos negócios causadas pela globalização.

Em sua justificativa, o trabalho ressaltou que o posicionamento geográfico brasileiro distante dos grandes centros consumidores mundiais, contribui para a redução da competitividade da cadeia de suprimentos com âmbito global, pela dimensão tempo.

A aplicabilidade do modelo foi verificada em estudo de caso com duas situações diferenciadas em empresas industriais de manufatura: uma empresa de porte grande e uma de porte médio, em setores de atividade econômica diferentes. O modelo se mostrou aplicável e útil para reduzir o tempo de suprimento na SCM, com estoque de segurança sendo mantido no país do comprador, com benefícios para as duas partes (vendedora e compradora).

Dessa maneira, entende-se que o objetivo principal do trabalho foi alcançado, ou seja, foi proposto um mode- lo aplicável a determinadas características de mercadorias e cadeias que efetivamente contribui para a redução do tempo de suprimento de material estrangeiro. Além disso, a utilização da legislação aduaneira, em pesquisa documental e descritiva, pode contribuir para ganhos de competitividade na SCM com âmbito global.

Uma contribuição do modelo proposto relaciona-se à sua aplicabilidade em empresas de manufatura, sem que haja a necessidade de mudanças no ambiente legal brasileiro para que o modelo se torne útil. A legislação aduaneira permite a oportunidade, que pode ser aproveitada pela empresa ao verificar as variáveis do modelo em suas mercadorias ou cadeias de suprimento. Outra contribuição é a dimensão de decisão composta por diversas variáveis, o que tende a diminuir eventuais análises mais superficiais.

O assunto desenvolvido no trabalho transitou por várias áreas de conhecimento, principalmente as relacionadas à SCM e à legislação aduaneira, o que pode ser considerado também como uma contribuição. Vários métodos e técnicas de pesquisa foram utilizados para suportar o trabalho, que pode ser considerado do tipo multimétodo. É importante também destacar que o modelo desenvolvido é um modelo teórico e que não se valeu de métodos estatísticos na sua verificação.

Além disso, o trabalho sugere que outros regimes aduaneiros especiais, no total de 16 , possam ser analisados sob a perspectiva da SCM, como forma de proporcionar avanços em termos de competitividade à indústria brasileira.

Como sugestão para trabalhos futuros, há o potencial de explorar métodos de análise multivariada, por setor de atividade industrial. Os resultados obtidos, dentro de um determinado setor, podem não apresentar as mesmas características em outros setores.

\section{Referências Bibliográficas}

BIANCHI, A. C. M.; ALVARENGA, M.; BIANCHI, R. Manual de Orientação: estágio supervisionado. 3. ed. São Paulo: Pioneira Thomson Learning, 2003. 98p.

BRASIL. Decreto $n^{\circ} 4.543$, de 26 de dezembro de 2002b. Regulamenta a administração das atividades aduaneiras, e a fiscalização, o controle e a tributação das operações de comércio exterior. Diário Oficial da República Federativa do Brasil: Poder Executivo, Brasília, DF, 27 dez. 2002. Disponível em: <http://www.receita.fazenda.gov. br/Legislacao/Decretos/2002/default.htm>. Acesso em: 02 jan. 2003.

BRASIL. Instrução Normativa $n^{\circ} 241$, de 06 de novembro de 2002a. Dispõe sobre o regime especial de entreposto aduaneiro na importação e na exportação. Diário Oficial da República Federativa do Brasil: Poder Executivo, Brasília, DF, 07 nov. 2002. Disponível em: <http://www. receita.fazenda.gov.br/Legislacao/ins/2002/default. htm>. Acesso em: 10 nov. 2002.

CARRETONI, E. Administração de Materiais: uma abordagem estrutural. 1. ed. Campinas: Alínea, 2000. 109 p.

CERVO, A. L.; BERVIAN, P. A. Metodologia Científica. 5. ed. São Paulo: Prentice Hall, 2002. 346p.

CHILDERHOUSE, P.; AITKEN, J.; TOWILL, D. R. Analysis and design of focused demand chains. Journal of Operations Management, Raleigh, v. 20, n. 6, p. 675-689, November 2002.

CHRISTOPHER, M.; TOWILL, D. R. Developing market specific supply chain strategies. The International Journal of Logistics Management, Badford-Ohio, v. 13, n.1, p. 1-12, July 2002.

COLUMBIA 60 anos. Disponível em: <http://www.columbia.com.br/historia>. Acesso em: 02 out. 2002.

DORNIER, P. P.; ERNST, R; FENDER; M.; KOUVELIS, P. 
Logística e Operações Globais: texto e casos. 1. ed. São Paulo: Atlas, 2000. 721 p.

FISHER, M. What is the right supply chain for your product? Harvard Business Review, Harvard, v. 1, n. 1, p. 105-116, March-April 1997.

GENTRY, J. J. The role of carriers in buyer-supplier strategic partnerships: a supply chain management approach. Journal of Business Logistics, Oak Brooks, v. 2, n. 17, p. 35-53, December 1996.

IMPORTADOS "made in Brazil". Portos e Navios, Rio de Janeiro, ed. 514, nov. 2003, p. 8-12.

LAKATOS, E. M.; MARCONI, M. A. Fundamentos de Metodologia Científica. 4. ed. São Paulo: Atlas, 2001. $288 \mathrm{p}$.

LARRAÑAGA, F. A. A Gestão Logística Global. 1. ed. São Paulo: Aduaneiras, 2003. 252 p.

MARTINS, G. A. Teorias e Modelos nas Ciências Administrativas. In: SEMINÁRIOS EM ADMINISTRAÇÃO FEA-USP, 6., 1999, São Paulo. Anais... São Paulo: SEMEAD, 1999. p. 12-19.

NAYLOR, J. B.; NAIM, M. M.; BERRY, D. Leagility: interfacing the lean and agile manufacturing paradigms in the total supply chain. International Journal of Production Economics, Linköping, v. 62, n. 3, p. 107-118, 1999.

PAGH, J. D.; COOPER, M. L. Supply chain postponement and speculation strategy: how to choose the right strategy. Journal of Business Logistics, Oak Brooks, v. 2, n. 19, p. 13-33, 1998.

PEREIRA, J. C. R. Análise de Dados Qualitativos: estratégias metodológicas para as ciências da saúde, humanas e sociais. 3. ed. São Paulo: EDUSP, 2001. 144 p.
PINTO, J. C. Avaliação estratégica do desempenho competitivo da manufatura: proposta de um modelo conceitual e flexível. 1998. 116 f. Dissertação (Mestrado em Engenharia Mecânica) - Faculdade de Engenharia Mecânica, Universidade Estadual de Campinas, Campinas, 1998.

PIRES, S. R. I. Managerial Implications of the Modular Consortium Model in a Brazilian Automotive Plant. International Journal of Operations \& Production Management, v. 18, n. 3, p. 221-232, March 1998.

PIRES, S. R. I. Gestão da Cadeia de Suprimentos: conceitos, estratégias, práticas e casos. 1. ed. São Paulo: Atlas, 2004. 310p.

SHIN, H.; COLLIER, D. A.; WILSON, D. D. Supply management orientation and supplier/buyer performance. Journal of Operations Management, Raleigh, v. 18, n. 3, p. 317-333, 2000.

VERGarA, S. C. Projetos e Relatórios de Pesquisa em Administração. 3. ed. São Paulo: Atlas, 2000. 323p.

VOLLMANN, T. E.; CORDON, C. Making Supply Chain Relationships Work. Institute of Management Development, Lausane, v. 1, n. 8, p. 26-37, 1996.

YIN, R. K. Case Study Research: Design and Methods. 2. ed. California: Sage Publications, 1994.

ZENDEJAS, V. S. Escala Likert: preguntas cerradas. Disponível em: <http://www.orion2000.org/documentos>. Acesso em: 22 jan. 2004.

ZINN, W. The New Logistics in Latin America: An Overview of Current Status and Opportunities. The International Journal of Logistics Management, BadfordOhio, v. 7, n. 1, p. 61-71, 1996.

\title{
A DECISION MODEL FOR THE CONSIGNATION OF IMPORTED MATERIAL IN SUPPLY CHAINS
}

\begin{abstract}
The globalization of international business, the paucity of international transportation routes to Brazil and the country's customs bureaucracy exert increasing pressure on manufacturers operating in Brazil to find alternatives to reduce the response time to customers without affecting costs. This article therefore presents a decision model for managing the consignation of imported materials in supply chains, whose development was based on several research methods, including the exploratory, the documental and case studies. A key factor in the proposed model is the definition of its set of decision variables. As the first step in the construction of this model, the initial set of proposed variables was tested and reviewed based on the experience of several importing companies that use special customs regimes. The model was subsequently tested at two companies located in Campinas, SP, Brazil, whose data indicate that the use of the model is feasible in certain chains and for goods with certain characteristics, taking advantage of Brazil's customs legislation as an opportunity to gain competitiveness within the context of global supply chain management.
\end{abstract}

Keywords: supply chain management, consignation, imported material. 